\title{
Çocuklar İçin Serbest Zaman Aktivite Anketi'nin Uyarlaması: Geçerlik ve Güvenirlik Çalışması
}

\author{
Adaptation of Children's Leisure Activities Study Survey: Validity and \\ Reliability Study
}

\author{
${ }^{1}$ Onur Deniz İŞLER \\ ${ }^{1}$ Necip DEMIRCI \\ ${ }^{1}$ Ayda KARACA
}

${ }^{1}$ Hacettepe Üniversitesi, Spor Bilimleri Fakültesi, Rekreasyon Bölümü, Fiziksel Aktivite ve Sağlık Anabilim Dalı

\section{Yazışma Adresi \\ Corresponding Address:}

Doc. Dr. Ayda KARACA

ORCID: 0000-0002-3189-2385

Hacettepe Üniversitesi Spor Bilimleri Fakültesi, Rekreasyon Bölümü, Fiziksel Aktivite ve Sağlık Anabilim Dalı

E-posta: ayda@hacettepe.edu.tr
Geliş Tarihi (Received): 23.12.2019 Kabul Tarihi (Accepted): 24.02.2020

\section{öz}

Bu çalışmanın amacı Telford, Salmon, Jolley ve Crawford tarafından 2004 yılında geliştirilen Çocuklar İçin Serbest Zaman Aktivite Anketi'nin (Children's Leisure Activities Study Survey) Türk kültürüne uyarlanması, geçerlik ve güvenirliğinin saptanmasıdır. 2017-2018 eğitim-öğretim yılında Ankara ilindeki ortaokullara devam eden ve yaşları 11 ile 14 arasında değişen toplam 405 öğrenci çalışmaya katılmayı gönüllü olarak kabul etmiştir. Anketin uyarlanması süreci iki aşamadan oluşmaktadır. Birinci aşamada İngilizceden Türkçeye çevrilmesi ve Türkçeden İngilizceye geri çevrilmesidir. İkinci aşamada ise Türkçe ifadelerin anlaşılırlığının test edilmesi için pilot uygulama gerçekleştirilmiştir. Sonrasında geçerlik çalışması için 104 öğrenciye bir haftalık fiziksel aktivite günlüğü dağıtılmıştır. Yedinci günün sonunda günlük formu öğrencilerden geri toplanmış ve Çocuklar İçin Serbest Zaman Aktivite Anketi aynı gün uygulanmıştır. Güvenirlik çalışması için 301 öğrenciye bir hafta arayla iki kez anket uygulanmıştır. Uyum geçerliğinin belirlenmesi için sınıf içi korelasyon katsayıları hesaplanmış ve anketin orta şiddetli, yüksek şiddetli ve orta-yüksek şiddetli fiziksel aktiviteleri içeren aktif bölümünün geçerli (SKK=0.50 ile 0.95 arasında; $p<0.05$ ) olduğu ancak düşük şiddetli aktiviteleri içeren inaktif bölümünün geçerli olmadığı ( $p>0.05$ ) saptanmıştır. Güvenirlik analizleri sonucunda ise sınıf içi korelasyon katsayılarının farklı şiddetteki aktivite türlerinde tüm yaş düzeyleri için (11-14 yaş) 0.52 ila 0.91 arasında değiştiği görülmüştür. Sonuç olarak; Çocuklar iç̧in Serbest Zaman Aktivite Anketi (ÇSZAA)'nin 1114 yaşları arasındaki çocuklarda düşük şiddetli (inaktif) aktivitelerin değerlendirilmesinde kullanılamayacağı ancak orta şiddetli, yüksek şiddetli ve ortayüksek şiddetli fiziksel aktivitelerin değerlendirilmesinde hem geçerli hem de güvenilir bir anket olması nedeniyle 11-14 yaşları arasındaki çocuklarda kullanılabileceği belirlenmiştir.

Anahtar Kelimeler: Serbest zaman fiziksel aktivitesi, Çocuklar, Geçerlik, Güvenirlik,

\section{ABSTRACT}

The aim of this study was to adapt the "Children's Leisure Activities Study Survey (CLASS)" developed by Telford, Salmon, Jolley, and Crawford in 2004, for Turkish language and culture and to determine its validity and reliability. The participants of the study consisted of who volunteered of 405 students aged 11 to 14 attending secondary school in Ankara in the 2017-2018 academic year. The process of adaptation of the questionnaire consisted of two steps. Translation and back-translation were conducted in the first step, and the intelligibility of Turkish expressions was tested in the second step. Afterward, the physical activity diary was applied for the past seven days to 104 students for the validity study. The physical activity diary was collected from the students at the end of the seventh day. And the questionnaire was applied to the students on the same day. For the reliability study, the questionnaire was administered to 301 students twice a week apart. Intraclass correlation coefficients for concurrent validity ranged between 0.50 and 0.95 for all age levels in the active part of the questionnaire $(p<0.05)$. But the inactive part of the questionnaire with lowintensity activities was found not valid ( $p>0.05$ ). As a result of the reliability analysis, it was found that the intraclass correlation coefficients ranged between 0.52 and 0.91 for all age levels (11-14) in different intensities of activities. As a result, CLASS can not be used to evaluate low-intensity activities in Turkish children aged 11-14. But, it is a valid and reliable questionnaire for the assessment of moderate intensity, vigorous intensity, and moderate to vigorous intensity physical activities.

Key Words: Leisure time physical activity, Children, Validity, Reliability, Questionnaire

Yazar Notu: Bu çalışma Doç. Dr. Ayda Karaca danışmanlığında Onur Deniz İSLER tarafindan Hacettepe Üniversitesi Sağlık Bilimleri Enstitüsü Spor Bilimleri ve Teknolojisi Anabilim Dalı'nda Yüksek Lisans Tezi olarak hazırlanmıştır. 13-16 Kasım 2019 tarihleri arasinda yapılan 17. Uluslararası Spor Bilimleri Kongresi'nde Sözel Bildiri olarak sunulmuştur. 


\section{GíRIŞ}

Fiziksel aktivite (FA); iskelet kaslarının kasılması sonucunda ortaya çıkan ve dinlenik düzeyin üzerinde enerji harcanmasını gerektiren her türlü vücut hareketi olarak tanımlanmaktadır (Caspersen ve diğ., 1985). Çocuklarda ve ergenlerde FA önerilerinin bazı kronik hastalıkların önlenmesinde önemli olduğu vurgulanmaktadır (World health Organisation [WHO], 2010). Bu bağlamda 6-17 yaşları arasındaki çocuk ve ergenlerin günde en az 60 dakika orta ve yüksek şiddetli FA yapmaları önerilmektedir (Janssen, 2007; Physical Activity Guidelines Advisory Committee [PAGAC], 2018; Piercy ve diğ., 2018). Orta-yüksek şiddetli FA'lar çocukların kardiyorespiratuvar (Porter ve diğ., 2017) ve kassal fiziksel uygunluğunun, kemik sağlığının ve sağlıklı vücut ağırlığının korunmasında önemli rol oynamaktadır (PAGAC, 2018). Diğer yandan, önerilen düzeyde düzenli FA yapmama olarak tanımlanan 'fiziksel inaktivite' ile bireyin uyanık olduğu sırada 1.5 metabolik eşdeğer (MET)'in altında enerji harcamasını gerektiren 'sedanter davranışlar' (Van der Ploeg ve Hillsdon, 2017) obezite, LDL kolesterolü, hipertansiyon gibi bulaşıcı olmayan kronik hastalıkların risk faktörlerini artırmaktadır (PAGAC, 2018). Buradan hareketle sedanter sürenin artışı, FA'dan bağımsız olarak özellikle aşırı kilo ve obezite riskinin artışıyla ilişkilendirilmekte ve mevcut çalışmalar, kilo kontrolü ve bulaşıcı olmayan kronik hastalıklar için sedanter davranışların değerlendirilmesinin önemini vurgulamaktadır (Van Dyck ve diğ., 2015). Bu bağlamda, FA ve sağlık arasındaki ilişkiyi anlamak (Chinapaw ve diğ., 2010) çocukların mevcut FA düzeylerinin tanımlanması ve FA düzeylerini artırmaya yönelik dizayn edilen müdahale programlarının etkisini değerlendirmek için, FA'nın doğru değerlendirilmesi oldukça önem taşımaktadır (Chinapaw ve diğ., 2010; Helmerhost ve diğ., 2012; Sirard ve Pate, 2001).

FA alanlarının bilinmesi müdahale çalışmaları açısından önemlidir. Çocuklar için FA alanları; beden eğitimi dersi, teneffüsler, organize sporlar, açık alan rekreasyonu, serbest zaman etkinlikleri, motor beceri gelişim programları, yürüyüş ve bisiklet sürme gibi okulda ve okul dışı zamanlarda, yapılandırılmış ve yapılandırılmamış formda pek çok aktiviteyi içeren kapsayıcı bir terimdir (Bangsbo ve diğ., 2016). Dolayısıyla çocuklarda FA alanlarına göre aktivite davranışlarının bilinmesi, yaşam boyu fiziksel olarak aktif yaşam biçimini geliştirmek adına gerekli olduğu ve buna yönelik ölçüm araçlarının geliştirilmesinin önem arz ettiği belirtilmektedir (Laguna ve diğ., 2013). Buna karşın çocuklarda FA'nın değerlendirilmesinde kullanılabilecek en iyi ölçüm aracının belirlenmesi oldukça güçtür (Hills ve diğ., 2014; Loprinzi ve Cardinal, 2011). İndirekt kalorimetri, gözlem yöntemi, akselerometre, günlük yöntemi, anket yöntemi gibi FA ve sedanter davranışın değerlendirilmesinde kullanılan geçerli ve güvenilir pek çok yöntem mevcuttur. Herbirinin güçlü ve zayıf yanları vardır. Bu nedenle ölçüm yöntemi belirlenirken çalışmanın amacı, örneklemin büyüklüğü, ölçüm aracının geçerlik ve güvenirliği, popülasyona uygunluğu, maliyeti vb. özellikler dikkate alınmalıdır (Karaca, 2017).

FA anketleri özellikle büyük örneklemi olan epidemiyolojik çalışmalarda (Chinapaw ve diğ., 2010; Loprinzi ve Cardinal, 2011) en çok tercih edilen yöntemlerden biridir (Hills ve diğ., 2014). Aktivitenin süresi, sıklı̆ğ, şiddetinin yanısıra tipi ve içeriği hakkında bilgi edinilebilmesi, relatif olarak kolay uygulanabilmesi ve maliyetinin düşük olması anketlerin tercih edilme sebepleri olarak sıralanabilir (Loprinzi ve Cardinal, 2011; Sirard ve Pate, 2001; Vanhees ve diğ., 2005). Ayrıca FA anketlerinin tercih edilme nedenleri arasında araştırmanın amacı ile bağlantılı olarak FA'nın hangi boyutlarının (Chinapaw ve diğ., 2010; Hills ve diğ., 2014) ve alanlarının (okul, ulaşım, ev, serbest zaman vb.) (Strath ve diğ., 2013) ölçülebildiği de yer almaktadır. Anketin uygulanma şekli, hatırlanması gereken zaman dilimi, değerlendirilmek istenilen FA boyutları, hesaplanan çıktı FA anketlerinin dikkate alınması gereken temel özelliklerindendir (Chinapaw ve diğ., 2010; Hills ve diğ., 2014). Ulusal alanyazın incelendiğinde Emlek Sert ve Temel (2014) tarafından "İlköğretim Öğrencileri için Fiziksel Aktivite Soru Formu" adıyla Türkçeye uyarlanan "Physical Activity Questionnaire for Older Children (PAQ-C)" ve Yerlisu Lapa ve diğ (2016) tarafından "Serbest Zaman Egzersiz 
Anketi” adıyla Türkçeye uyarlanan "Leisure Time Exercise Questionnaire” olmak üzere iki anket mevcut olup, bu anketler FA boyutlarının (süresi, sıklığı, şiddeti, tipi) tamamını içermemektedir. FA düzeyini belirlemek amacıyla uluslararası alanyazında farklı popülasyonlar için geliştirilen farklı uzunlukta, farklı hatırlama süresini ve farklı aktiviteleri içeren FA anketleri mevcuttur (Chinapaw ve diğ., 2010). Çocuklar İçin Serbest Zaman Aktivite Anketi (ÇSZAA)'nin tüm FA alanlarının elde edilebildiği az sayıda anketten biri olduğu görülmüştür (Chinapaw ve diğg., 2010; Telford ve diğ., 2004).

Ulusal alanyazında aktivitenin tüm boyutlarını aynı anda içeren Türkçeye uyarlanmış ya da Türk çocukları için geliştirilmiş FA anketlerine rastlanmamıştır. Dolayısıyla Telford, Salmon, Jolley ve Crawford tarafından 2004 yılında geliştirilen Çocuklar için Serbest Zaman Aktivite Anketi'nin (Children’s Leisure Activities Study Survey-CLASS) Türk kültürüne uyarlanması ile çocuklarda FA'nın değerlendirilmesinde önemli bir boşluğun doldurulacağı öngörülmüştür. Ayrıca ÇSZAA'nın çocukların sadece FA düzeyini değil, aktivitelerin türünü, şiddetini, sıklığını da ölçmesi nedeniyle çocuklarda FA alanında yapılacak araştırmalar için alanyazına önemli katkılar sağlayacağı düşünülmektedir. Buradan hareketle bu çalışmanın amacı Telford, Salmon, Jolley ve Crawford tarafından 2004 yılında geliştirilen "Çocuklar İçin Serbest Zaman Aktivite Anketi”nin (Children's Leisure Activities Study Survey) Türk kültürüne uyarlanması, geçerlik ve güvenirliğinin saptanmasıdır.

\section{YÖNTEM}

Araştırma Grubu: Araştırma grubu, 2017-2018 eğitim-öğretim yılı Şubat ve Nisan ayları arasında Ankara ilinde üç farklı ilçede (Çankaya, Mamak, Etimesgut) yer alan toplam yedi ortaokulda 5-8. sınıfa devam eden yaşları 11 ile 14 arasında değişen 467 öğrencinin (geçerlik çalışması: 137 öğrenci; güvenirlik çalışması: 330 öğrenci) gönüllü katılımı ile oluşturulmuştur. Amaca yönelik örnekleme yöntemi ile seçilen öğrencilerin 62'si (geçerlik çalışması: 33 öğrenci; güvenirlik çalışması: 29 öğrenci) veri toplama araçlarını eksik doldurmaları ya da toplanan verilerin okunaksız olması nedeniyle verilerin analizi sürecine dâhil edilmemiş ve toplam 405 öğrenci (geçerlik çalışması: 104 öğrenci; güvenirlik çalışması: 301 öğrenci) ile çalışma tamamlanmıştır.

Etik kurul izni Hacettepe Üniversitesi Girişimsel Olmayan Klinik Araştırmalar Etik Kurulu'ndan (GO 16/14-18), okullarda veri toplanabilmesi için izin Ankara Valiliği Milli Eğitim Müdürlüğü'den (sayı: 14588481-605.99-E.5591581) alınmıştır.

Veri Toplama Araçları: Bu çalışmada veri toplama aracı olarak Çocuklar için Serbest Zaman Aktivite Anketi, fiziksel aktivite günlüğü ve kişisel biligi formu kullanılmıştır.

Çocuklar için Serbest Zaman Aktivite Anketi (ÇSZAA): Çocuklar için Serbest Zaman Aktivite Anketi (Children's Leisure Activities Study Survey-CLASS), 10-12 yaşları arasındaki Avustralyalı çocukların FA ve sedanter davranışların türünü, sıklığını ve süresini değerlendirmek için Telford, Salmon, Jolley, and Crawford tarafından 2004 yılında kendini rapor etme (bireysel bildirim) anketi olarak geliştirilmiştir. Anketin orijinal formunda, 31 fiziksel aktivite ve 14 sedanter davranışın listesi bulunmaktadır. Ankette her FA için tipik bir hafta içinde (Pazartesi'den Cuma'ya) ve tipik bir hafta sonunda (Cumartesi ve Pazar) ilgili aktiviteyi yapıp yapmadıklarını belirten "EVET" veya "HAYIR" seçeneklerinden birini daire içine almaları istenmektedir. "Tipik hafta” kavramı ile mevcut okul dönemi düşünülmüş ve bu sürece okul tatilleri dâhil edilmemiştir. Yaptıkları aktiviteler için "EVET"i işaretleyen çocuklardan Pazartesi-Cuma ve Cumartesi-Pazar günleri için aktivitenin sıklığını ve bu aktivitede geçirdikleri toplam süreyi (dakika veya saat) bildirmeleri istenmektedir. Anketin sedanter davranış bölümünde ise davranışların sıklığı sorulmayıp sedanter geçirilen toplam zamanı (Pazartesi-Cuma ve Cumartesi-Pazar günleri arasında dakika veya saat cinsinden) bildirmeleri 
istenmektedir. Anketin hem FA (aktif) hem de sedanter davranışlar (inaktif) bölümünde, ankette yer almayan ancak çocukların genellikle yaptığı aktiviteler/davranışlar için “diğer” seçeneği yer almaktadır.

Fiziksel Aktivite Günlüğ̈̈: Araştırmacılar tarafından oluşturulan FA günlüğü formu kullanılarak çocuklardan haftanın her gününü sabah, öğle ve akşam olmak üzere üç farklı zaman dilimine ait "oturma”, “yürüme” ve "koşma, zıplama, spor yapma, hareketli olma” sürelerini (günde kaç saat ya da dakika) içermektedir.

Kişisel Bilgi Formu: Araştırmacılar tarafından hazırlanan kişisel bilgi formu yaş, cinsiyet vb. bilgileri içermektedir.

Verilerin Toplanması: Verilerin toplanması anketin kültürel uyarlaması, geçerlik ve güvenirlik çalışmaları olmak üzere üç aşamada gerçekleştirilmiştir.

Çocuklar için Serbest Zaman Aktivite Anketi’nin Kültürel Uyarlama Çalışması: Telford ve diğerleri tarafından 2004 yılında geliştirilen anketin Türkçeye çevrilme süreci, iki aşamadan oluşmaktadır. Birinci aşaması dilbilim alanında uzman iki öğretim elemanı (Türkçe ve İngilizce dilinde uzman) ve spor bilimleri alanında uzman üç öğretim elemanı tarafından anketin orijinal dili İngilizceden Türkçeye ve Türkçeden tekrar İngilizceye çevrilmesi (translation, back translation) iken, ikinci aşaması Türkçe ifadelerin anlaşılırlığının pilot uygulama ile ortaokul öğrencilerine uygulanıp netleştirilmesidir.

Ankette yer almayan ancak ülkemizdeki çocuklar tarafından sıklıkla yapıldığı düşünülen bazı aktivitelerin ankete eklenme sürecinde ise spor bilimleri alanında uzman kişilerin görüşleri alınmıştır. Toplam yedi FA (halk oyunları, voleybol, saklambaç, yakan top, taekwondo/karate/judo, tempolu koşu ve playstation move/nintendo wii/bilgisayar oyunlar1-hareket ederek) ve bir sedanter davranış (telefonda oyun oynamak) ankete yeni maddeler olarak eklenmiştir. Bunun yanı sıra anketin geliştirildiği Avustralya kültüründe yer alan ancak Türk kültüründe olmadığı düşünülen altı FA (kriket, netbol, beyzbol, down ball, Aussie Rules Football, bahçedeki oyun evinde oyun oynamak) ve bir sedanter davranış (hayali oyun) anketin Türkçe formundan çıkarılmıştır. Ayrıca anketin orijinal formunda "evcil hayvanlarla oynama" ve “köpekle yürüme” olarak iki ayrı aktivite şeklinde belirtilen aktiviteler "köpekle oynama/yürüyüş” şeklinde ifade edilerek tek bir madde haline getirilmiştir. Sonuç olarak, anketin Türkçe formunda 30 fiziksel aktivite ve 14 sedanter davranıştan oluşan bir liste oluşturulmuştur. Anketin orijinal formundaki gibi ankette yer almayan ancak çocukların eklemek istedikleri aktiviteler/davranışlar için “diğer” seçeneği yer almaktadır. Türkçeye çevirilmiş olan anketin, anlaşılırlığını test etmek için anket her sınıf düzeyinden (5, 6, 7 ve 8. sınıf) toplam 87 (49 kız, 38 erkek) öğrenciye uygulanarak pilot çalışma gerçekleştirilmiştir. Pilot uygulamada olumlu geri bildirimler alınmış ve uygulama sonucunda anketin anlaşılırlığ hakkında herhangi bir sorun olmadığı tespit edilmiştir.

Çocuklar için Serbest Zaman Aktivite Anketi'nin Geçerlik Çalışması: ÇSZAA'nın geçerliğinin saptanması amacıyla FA günlüğü formu öğrencilere sınıf ortamında dağıtılmış ve formları nasıl dolduracakları açıklanmıştır. Öğrencilerden FA günlüğü formlarını bir hafta içerisinde her gün, günün belirtilen zaman dilimlerinde doldurmaları istenmiştir. Bir hafta sonrasında günlük formları öğrencilerden geri alındığında, ÇSZAA kendini değerlendirme yöntemiyle sınıf ortamında uygulanmıştır.

Çocuklar için Serbest Zaman Aktivite Anketi'nin Güvenirlik Çalışması: ÇSZAA'nın güvenirlik katsayısının belirlenmesi amacıyla okullara bir hafta arayla iki ziyaret (test-tekrar test) gerçekleştirilmiştir. ÇSZAA sınıf ortamında kendini değerlendirme yöntemi ile uygulanmıştır.

Verilerin Analizi: Çocuklar için Serbest Zaman Aktivite Anketi ile fiziksel aktivite günlüğünün analizi ve istatistiksel analiz olmak üzere iki başlık altında ele alınmıştır. 
ÇSZAA ve FA günlüğünün Analizi: FA günlüğü'nden elde edilen farklı şiddetteki aktiviteler için haftanın her gününü sabah, öğle ve akşam olmak üzere üç farklı zaman dilimine ait "oturma”, "yürüme” ve "koşma, zıplama, spor yapma, hareketli olma" süreleri (günde kaç saat ya da dakika) belirlenmiş ve MET/hafta değerleri hesaplanmıştır. ÇSZAA'dan elde edilen enerji tüketimlerini hesaplamak için farklı şiddetteki aktivitelerin (düşük, orta, yüksek ve ortayüksek) süreleri belirlenmiş ve MET/hafta değerleri hesaplanmıştır. Hem FA günlüğü formu hem de ÇSZAA için harcanan enerjinin (MET/hafta) hesaplanması için kullanılan MET değerleri Ainsworth ve arkadaşlarının (2000) çalışmasından alınmıştır. FA'nin şiddetine göre sınıflandırılmasında, çoğunlukla MET değeri referans olarak kullanılmaktadır (WHO, 2010). Buna göre aktiviteler MET değerlerine göre düşük, orta, yüksek, orta-yüksek olarak sınıflandırılmıştır. Düşük şiddetli aktiviteler saatte 3 MET'in altında enerji harcamasına neden olan aktivitelerdir. OrtaYüksek Şiddetli Fiziksel Aktivite (OYŞFA); orta şiddetli fiziksel aktiviteler ile yüksek şiddetli fiziksel aktivitelerin toplamından elde edilmektedir. ÇSZAA'da yer alan fiziksel aktiviteler orta şiddetli fiziksel aktiviteler (3.0-5.9 MET), Yüksek Şiddetli Fiziksel Aktiviteler (6 MET ve üzeri) ve OYŞFA (3 MET ve üzeri) olarak ele alınmıştır.

Istatistiksel Analiz: Geçerlik katsayısının belirlenmesi amacıyla, FA günlüğü ve ÇSZAA'dan elde edilen enerji harcaması değerleri arasındaki ilişki her iki yöntemden elde edilen birimlerin (MET/hafta) aynı olması nedeniyle Sınıf içi Korelasyon Katsayısı (SKK) kullanılarak hesaplanmıştır. Güvenirlik katsayısının belirlenmesi amacıyla bir hafta arayla iki kez uygulanan ÇSZAA'dan elde edilen enerji harcaması değerleri arasındaki ilişki SKK kullanılarak hesaplanmıştır. Yanılma düzeyi 0.05 olarak belirlenmiştir. ÇSZAA'nın geçerlik ve güvenirliğinin belirlendiği bu çalışmada Sınıf içi Korelasyon Katsayısının kabul edilebilir seviyeleri Landis ve Koch’a (1977) göre "0 hiç; 0.01-0.20 zayıf; 0.21-0.40 orta; 0.41-0.60 iyi; 0.61-0.80 çok iyi; 0.81-1.00 neredeyse mükemmel” olarak sınıflandırılmıştır.

\section{BULGULAR}

ÇSZAA'nın Geçerliğine İlişkin Bulgular: ÇSZAA'dan ve FA günlüğünden elde edilen düşük, orta, yüksek, OYŞFA'lar için haftalık toplam MET değerleri (MET/hafta) arasındaki ilişki sınıf içi korelasyon katsayısı kullanılarak hesaplanmış ve uyum geçerliğine ilişkin bulgular Tablo 1 ve 2'de sunulmuştur.

Tablo 1. Düşük şiddetli fiziksel aktiviteler için ÇSZAA ile fiziksel aktivite günlüğü arasındaki geçerlik katsayıları

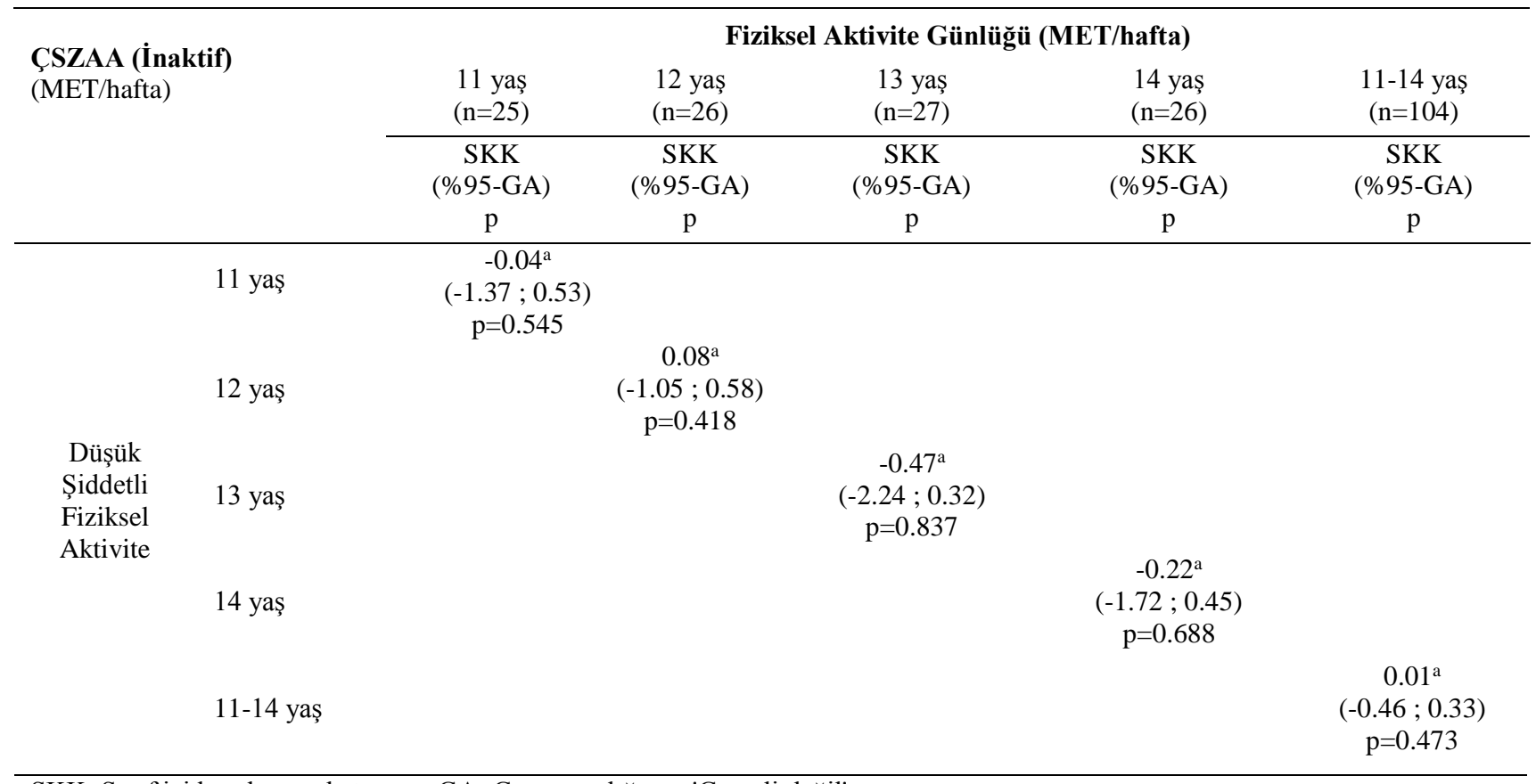


Tablo 1'de ÇSZAA'nın düşük şiddetli aktiviteleri içeren (inaktif) bölümünden elde edilen sınıf içi korelasyon katsayılarının istatistiksel olarak anlamlı olmadığı saptanmıştır ( $\mathrm{p}>0.05)$.

Tablo 2. Farklı şiddetteki fiziksel aktiviteler için ÇSZAA ile fiziksel aktivite günlügü arasındaki geçerlik katsayıları

\begin{tabular}{|c|c|c|c|c|c|}
\hline \multirow{3}{*}{$\begin{array}{l}\text { ÇSZAA } \\
\text { (Aktif) } \\
\text { (MET/hafta) }\end{array}$} & \multicolumn{5}{|c|}{ Fiziksel Aktivite Günlüğü (MET/hafta) } \\
\hline & $\begin{array}{l}11 \text { yaş } \\
(\mathrm{n}=25)\end{array}$ & $\begin{array}{l}12 \text { yaş } \\
(\mathrm{n}=26)\end{array}$ & $\begin{array}{l}13 \text { yaş } \\
(\mathrm{n}=27)\end{array}$ & $\begin{array}{l}14 \text { yaş } \\
(\mathrm{n}=26)\end{array}$ & $\begin{array}{l}11-14 \text { yaş } \\
(\mathrm{n}=104)\end{array}$ \\
\hline & $\begin{array}{c}\text { SKK } \\
(\% 95-G A) \\
p\end{array}$ & $\begin{array}{c}\text { SKK } \\
(\% 95-\mathrm{GA}) \\
\mathrm{p}\end{array}$ & $\begin{array}{c}\text { SKK } \\
(\% 95-\mathrm{GA}) \\
\mathrm{p}\end{array}$ & $\begin{array}{c}\text { SKK } \\
(\% 95-\mathrm{GA}) \\
\mathrm{p}\end{array}$ & $\begin{array}{c}\text { SKK } \\
(\% 95-G A) \\
p\end{array}$ \\
\hline $\begin{array}{l}\text { Orta Şiddetli Fiziksel } \\
\text { Aktiviteler }\end{array}$ & $\begin{array}{c}0,63^{\mathrm{c}} \\
(0.16 ; 0.83) \\
\mathrm{p}=0.009\end{array}$ & $\begin{array}{c}0.57^{\mathrm{b}} \\
(0.06 ; 0.81) \\
\mathrm{p}=0.017\end{array}$ & $\begin{array}{c}0.78^{\mathrm{c}} \\
(0.51 ; 0.90) \\
\mathrm{p}=0.000\end{array}$ & $\begin{array}{c}0.54^{\mathrm{b}} \\
(-0.00 ; 0.79) \\
\mathrm{p}=0.026\end{array}$ & $\begin{array}{c}0.59^{\mathrm{b}} \\
(0.40 ; 0,72) \\
\mathrm{p}=0.000\end{array}$ \\
\hline $\begin{array}{l}\text { Yüksek Şiddetli Fiziksel } \\
\text { Aktiviteler }\end{array}$ & $\begin{array}{c}0.50^{\mathrm{b}} \\
(-0.12 ; 0.78) \\
\mathrm{p}=0.047\end{array}$ & $\begin{array}{c}0,63^{\mathrm{c}} \\
(0.18 ; 0.83) \\
\mathrm{p}=0.008\end{array}$ & $\begin{array}{c}0.65^{\mathrm{c}} \\
(0.23 ; 0,84) \\
\mathrm{p}=0.005\end{array}$ & $\begin{array}{c}0,69^{\mathrm{c}} \\
(0.49 ; 0.84) \\
\mathrm{p}=0.005\end{array}$ & $\begin{array}{c}0,65^{\mathrm{c}} \\
(0.49 ; 0,76) \\
\mathrm{p}=0.000\end{array}$ \\
\hline $\begin{array}{l}\text { Orta-Yüksek Şiddetli } \\
\text { Fiziksel Aktiviteler } \\
\text { (OYŞFA) }\end{array}$ & $\begin{array}{c}0,71^{\mathrm{c}} \\
(0.34 ; 0.87) \\
\mathrm{p}=0.002\end{array}$ & $\begin{array}{c}0.70^{\mathrm{c}} \\
(0.33 ; 0.86) \\
\mathrm{p}=0.002\end{array}$ & $\begin{array}{c}0.69^{\mathrm{c}} \\
(0.33 ; 0.86) \\
\mathrm{p}=0.002\end{array}$ & $\begin{array}{c}0.95^{\mathrm{d}} \\
(0.89 ; 0.97) \\
\mathrm{p}=0.000\end{array}$ & $\begin{array}{c}0.77^{\mathrm{c}} \\
(0.65 ; 0.84) \\
\mathrm{p}=0.000\end{array}$ \\
\hline
\end{tabular}

SKK: Sınıf içi korelasyon katsayısı, GA: Güven aralığı, b: 'İyi' düzeyde, c: 'Çok iyi' düzeyde, d:'Nerdeyse mükemmel' düzeyde.

Tablo 2'de, ÇSZAA'nın geçerlik katsayılarının farklı şiddetteki aktivitelerde tüm yaş düzeyleri için 'iyi' ve 'neredeyse mükemmel' arasında değiştiği ve ÇSZAA'nın düşük, orta, yüksek ve orta-yüksek şiddetli aktiviteler için kullanılabilecek geçerli $(\mathrm{p}<0.05)$ bir anket olduğu görülmektedir (Tablo 2).

ÇSZAA'nın Güvenirliğine İlişkin Bulgular: Çocuklar İçin Serbest Zaman Aktivite Anketi’nin güvenirliğini değerlendirmek amacıyla bir hafta arayla uygulanan test-tekrar test sınıf içi korelasyon testi sonuçları Tablo 3’te gösterilmiştir.

Tablo 3. Farklı şiddetteki fiziksel aktiviteler için ÇSZAA'nın test-tekrar test güvenirliği

\begin{tabular}{|c|c|c|c|c|c|}
\hline ÇSZAA & $\begin{array}{l}11 \text { yaş } \\
(n=78)\end{array}$ & $\begin{array}{l}12 \text { yaş } \\
(n=85)\end{array}$ & $\begin{array}{l}13 \text { yaş } \\
(n=72)\end{array}$ & $\begin{array}{l}14 \text { yaş } \\
(n=66)\end{array}$ & $11-14$ yaş $(n=301)$ \\
\hline \multirow[t]{2}{*}{ (MET/hafta) } & $\begin{array}{c}\text { SKK } \\
(\% 95-\mathrm{GA})\end{array}$ & $\begin{array}{c}\text { SKK } \\
(\% 95-\mathrm{GA})\end{array}$ & $\begin{array}{c}\text { SKK } \\
(\% 95-G A)\end{array}$ & $\begin{array}{c}\text { SKK } \\
(\% 95-\mathrm{GA})\end{array}$ & $\begin{array}{c}\text { SKK } \\
(\% 95-\mathrm{GA})\end{array}$ \\
\hline & $\mathrm{p}$ & $\mathrm{p}$ & $\mathrm{p}$ & $\mathrm{p}$ & $\mathrm{p}$ \\
\hline Düşük Şiddetli FA & $\begin{array}{c}0.84^{\mathrm{d}} \\
(0.76 ; 0.90) \\
\mathrm{p}=0.000\end{array}$ & $\begin{array}{c}0.86^{\mathrm{d}} \\
(0.79 ; 0.91) \\
\mathrm{p}=0.000\end{array}$ & $\begin{array}{c}0.70^{\mathrm{c}} \\
(0.53 ; 0.81) \\
\mathrm{p}=0.000\end{array}$ & $\begin{array}{c}0.91^{\mathrm{d}} \\
(0.86 ; 0.95) \\
\mathrm{p}=0.000\end{array}$ & $\begin{array}{c}0.82^{\mathrm{d}} \\
(0.77 ; 0.85) \\
\mathrm{p}=0.000\end{array}$ \\
\hline Orta Şiddetli FA & $\begin{array}{c}0.81^{\mathrm{d}} \\
(0.71 ; 0.88) \\
\mathrm{p}=0.000\end{array}$ & $\begin{array}{c}0.78^{c} \\
(0.67 ; 0.86) \\
\mathrm{p}=0.000\end{array}$ & $\begin{array}{c}0.52^{\mathrm{b}} \\
(0.24 ; 0.70) \\
\mathrm{p}=0.000\end{array}$ & $\begin{array}{c}0.68^{\mathrm{c}} \\
(0.48 ; 0.80) \\
\mathrm{p}=0.000\end{array}$ & $\begin{array}{c}0.73^{\mathrm{c}} \\
(0.66 ; 0.78) \\
\mathrm{p}=0.000\end{array}$ \\
\hline Yüksek Şiddetli FA & $\begin{array}{c}0.90^{\mathrm{d}} \\
(0.85 ; 0.94) \\
\mathrm{p}=0.000\end{array}$ & $\begin{array}{c}0.83^{\mathrm{d}} \\
(0.74 ; 0.89) \\
\mathrm{p}=0.000\end{array}$ & $\begin{array}{c}0.88^{\mathrm{d}} \\
(0.81 ; 0.92) \\
\mathrm{p}=0.000\end{array}$ & $\begin{array}{c}0.89^{\mathrm{d}} \\
(0.83 ; 0.93) \\
\mathrm{p}=0.000\end{array}$ & $\begin{array}{c}0.87^{\mathrm{d}} \\
(0.84 ; 0.90) \\
\mathrm{p}=0.000\end{array}$ \\
\hline $\begin{array}{l}\text { Orta-Yüksek Şiddetli } \\
\text { FA }\end{array}$ & $\begin{array}{c}0.85^{\mathrm{d}} \\
(0.77 ; 0.91) \\
\mathrm{p}=0.000\end{array}$ & $\begin{array}{c}0.78^{c} \\
(0.67 ; 0.86) \\
p=0.000\end{array}$ & $\begin{array}{c}0.69^{\mathrm{c}} \\
(0.51 ; 0.81) \\
\mathrm{p}=0.000\end{array}$ & $\begin{array}{c}0.75^{\mathrm{c}} \\
(0.59 ; 0.84) \\
\mathrm{p}=0.000\end{array}$ & $\begin{array}{c}0.79^{\mathrm{c}} \\
(0.74 ; 0.83) \\
\mathrm{p}=0.000\end{array}$ \\
\hline
\end{tabular}

SKK: Sınıf içi korelasyon katsayısı, GA: Güven aralığı, b: '̇yi' düzeyde, c: 'Çok iyi' düzeyde, d:'Nerdeyse mükemmel' düzeyde.

Tablo 3'te, ÇSZAA'nın test-tekrar test güvenirlik katsayılarının farklı şiddetteki aktivitelerde tüm yaş düzeyleri için 'iyi' ve 'neredeyse mükemmel' arasında değiştiği ve ÇSZAA'nın düşük, orta, yüksek ve orta-yüksek şiddetli aktiviteler için kullanılabilecek güvenilir $(\mathrm{p}<0.05)$ bir anket olduğu görülmektedir (Tablo 3 ). 


\section{TARTIŞMA}

Süresi, sıklığı, şiddeti ve tipi açısından değişkenlik gösterebilen FA'nın özellikle çocuklarda ve ergenlerde ölçülmesi zordur (Ridley ve diğ., 2006). Bu açıdan bakıldığında FA'nın dört farklı boyutunun subjektif yöntemle değerlendirilmesinde kullanılabilecek FA ölçüm aracının alanyazına kazandırılmasının önemli olduğu düşünülmektedir. Dolayısıyla bu çalışma 11-14 yaşları arasındaki çocuklarda ÇSZAA'nın Türkçe versiyonunun düşük şiddetli, orta şiddetli, yüksek şiddetli ve orta-yüksek şiddetli FA'lara ilişkin güvenirlik ve geçerliğinin saptanması amacıyla yapılmıştır.

Bu çalışmada ÇSZAA'nın düşük şiddetli FA'ları içeren inaktif bölümünden elde edilen enerji harcaması (MET/hafta) ile FA günlüğünde yer alan oturma aktivitesinden elde edilen enerji harcaması (MET/hafta) arasındaki sınıf içi korelasyon katsayısının çok düşük düzeyde ve istatistiksel olarak anlamlı olmadığı görülmüştür (p>0.05) (Bkz. Tablo 1). Dolayısıyla Çocuklar İçin Serbest Zaman Aktivite Anketi'nin düşük şiddetli aktiviteleri içeren inaktif bölümünün Türk Çocuklarında geçerli olmadığı saptanmıştır. Telford ve diğ. (2004) tarafından yapılan orjinal çalışmada ÇSZAA'nın geçerlik katsayısının düşük olduğu, Huang ve diğ. (2009) tarafından Çinceye uyarlanan ÇSZAA'nın düşük aktiviteler için geçerlik katsayısının 0.25 olduğu görülmüsşür. Ayrıca Helmerhost ve diğ. (2012) tarafindan yayımlanan sistematik derlemede gençler için geliştirilen FA anketlerinin çoğunun geçerlik katsayısının 0.25-0.41 arasında değiştiğini, çok azının geçerlik katsayısının iyi düzeyde olduğu belirtilmiştir. Lachat ve diğ. (2008) tarafından Vietnamlı adölesanlar üzerinde yapılan çalışmada IPAQ ve PAQA'nın düşük şiddetli fiziksel aktiviteler için geçerlik katsayısı düşük (sırasıyla; Sperman r=0.14; Sperman r=0.20) bulunmuştur. Bobakova ve diğ. (2015) tarafından yapılan çalışmada sedanter davranışlarına (TV izleme, bilgisayar kullanma ve oturma süresine) ait sınıf içi korelasyon katsayılarının orta düzeyde olduğu (SKK: 0.51 ila $\mathrm{SKK}=0.62$ arasında değiştiği) belirtilmiştir. Hem bu çalışmada hem de yukarıda belirtilen diğer çalışmalarda düşük şiddetli aktivitelere ait korelasyon katsayılarının orta ve yüksek şiddetteki aktivitelerden daha düşük olduğu görülmektedir.

Sedanter davranışların anketlerle değerlendirilmesi en zor olan alanlardan biri olması (Helmerost ve diğ., 2012) ve düşük-orta şiddetli aktivitelerin hatırlanmasında doğruluğun düşük olması gibi nedenler (Strath ve diğ., 2004), bu çalışmanın düşük şiddetli aktiviteler (inaktif) bölümünün geçerli olmamasını açılayabilir. Ayrıca geçmişte yapılan FA'yı hatırlamanın oldukça karmaşık bilişsel bir görev olduğu vurgulanmaktadır (Chinapaw ve diğ., 2010). Bilişsel olarak olgunlaşmamış olan gençlerde FA'nın kendini değerlendirme yöntemiyle uygulanmasında zorlukların olmasının yanı sıra hatırlama ya da kavrama ile ilgili bilişsel sınırlılıklar nedeniyle ölçüm hatalarıyla karşı karşıya kalınabilir. (Helmerost ve diğ., 2012). Çocuklarda ve yetişkinlerde gün içerisinde sedanter sürenin oluşum modelinin farklı seyrettiği belirtilmektedir. Zira çocukların sedanter sürelerinin evreleri yetişkinlere kıyasla daha kısa sürelerle gerçekleşebilmektedir. $\mathrm{Bu}$ durum çocukların daha fazla sıklıkla sedanter sürelerinin kesintiye uğramasına yol açabilmektedir (Altenburg ve Chinapaw, 2015). Dolayısıyla kendini değerlendirme yöntemi kullanılarak yapılan değerlendirmelerde gençlerden elde edilen verilerin doğruluğu (özellikle de detaylı hatırlama ve soyut düşünme yeteneğinde) yetişkinlerden daha düşük olduğu bilinmektedir (Chinapaw ve diğ., 2010; Welk ve diğ., 2000).

Bu çalışmada orta, yüksek, orta-yüksek şiddetli aktivitelerden elde edilen geçerlik bulguları incelendiğinde; orta şiddetli aktivitelerin sınıf içi korelasyon katsayısının 0.54 ile 0.78 arasında, yüksek şiddetli aktivitelerin sınıf içi korelasyon katsayısının 0.50 ile 0.69 arasında; orta-yüksek şiddetli aktivitelerin sınıf içi korelasyon katsayısının ise 0.69 ile 0.95 arasında değiştiği görülmektedir ( $<<0.05$ ) (Bkz. Tablo 2). Dolayısıyla Çocuklar İçin Serbest Zaman Aktivite Anketi'nin orta, yüksek ve orta-yüksek şiddetli aktiviteleri içeren 'aktif' bölümünün geçerlik düzeyinin 'iyi' ve 'neredeyse mükemmel' arasında değiştĭgi ve 11-14 yaşları arasındaki çocuklarda yapılan araştırmalarda kullanılabileceği belirlenmiştir. 
ÇSZAA'nın 10-12 yaş çocuklarına uygulanan orjinal versiyonunda, geçerlik katsayısının yüksek şiddetli fiziksel aktivitelerde $(r=0.24 ; \mathrm{p}<0.05)$ diğer aktivite şiddetlerinden daha yüksek değere sahip olduğu gösterilmiştir (Telford ve diğ., 2004). Benzer şekilde Huang ve diğ. (2009) tarafından ÇSZAA'nın Çin kültürüne uyarlamasının yapıldığı çalışmada yüksek şiddetli fiziksel aktivitelerden elde edilen geçerlik katsayılarının düşük ve orta şiddetli aktivitelere göre daha yüksek (kız çocukları için 0.43) olduğu görülmektedir. Alanyazın incelendiğinde genellikle geçerlik çalışmalarının göreceli olarak düşük olduğu söylenebilir. Lachat ve diğerlerinin (2008) Vietnamlı adölesanlar üzerinde yaptıkları çalışmada Uluslararası Fiziksel Aktivite Anketi ve Physical Activity Questionnaire for Adolescents (PAQA)'in kriter geçerliği katsayısının her iki anket için de düşük olduğunu (sırasıyla; $\rho=0.21$ ve $\rho=0.27$ ) belirtmişlerdir. Wong ve diğ. (2006) tarafından 6-12. sınıf öğrencileri üzerinde yapılan çalışmada School Health Action, Planning and Evaluation System (SHAPES) kullanılarak hesaplanan orta-yüksek şiddetli fiziksel aktivite süresine ait (dk) geçerlik katsayısının (Spearman $r=0.44 ; p<0.01$ ) kabul edilebilir düzeyde olduğu ancak orta şiddetli fiziksel aktiviteler ile yüksek şiddetli fiziksel aktivitelerin geçerlik katsayısının kabul edilebilir düzeyde olmadığı ( $>0.05)$ belirtilmiştir. Janz ve diğ. (2008) tarafından geçerlik çalışması yapılan Physical Activity Questionnaire for Adolescents (PAQ-A)'in orta-yüksek şiddetli fiziksel aktivitelere ilişsin Spearman korelasyon katsayısı $0.63(\mathrm{p}<0.05)$ bulunmuştur. Modifiye edilmiş Physical Activity Questionnaire for Adolescents (PAQ-A)'in orta-yüksek şiddetli aktivitelerinin geçerliği (objektif yönteme karşı) $(r=0.39)$ düşük düzeydedir $(\mathrm{p}<0.01$ ) (Aggio ve diğ., 2016). Bu çalışmada ise orta şiddetli, yüksek şiddetli ve orta-yüksek şiddetli fiziksel aktivitelerde diğer çalışmaların çoğundan daha yüksek düzeyde geçerlik katsayısı elde edilmiştir (Bkz. Tablo 2). Bunun nedeni, yüksek şiddetli fiziksel aktivitelerin daha düşük şiddetli aktivitelere göre daha yapılandırılmış, alışılmış ya da farklı olmasından dolayı çocuklar tarafından daha kolay hatırlanabilmesi olabilir (Welk ve diğ., 2007). Ayrıca gençlerin aktivite modellerinin, yetişkinlerden çok daha fazla değişken ve kesikli olması (Chinapaw ve diğ., 2010; Corder ve diğ., 2009), aktivite şiddeti hesaplanırken yetişkinler için kullanılan metabolik eşdeğerin çocuklar için de kullanılması geçerlik katsayılarının çok yüksek olmamasının nedenlerinden olabilir (Corder ve diğ., 2009).

Çocuklar İçin Serbest Zaman Aktivite Anketi'nden elde edilen bulgular, anketin her yaş düzeyinde (11, 12, 13 ve 14 yaşlar için ayrı ayrı ve 11-14 yaş için) ve her aktivite şiddetinde 'iyi' ila 'neredeyse mükemmel' arasında güvenilir olduğunu göstermektedir (Bkz. Tablo 3). ÇSZAA'nın 10-14 yaş çocuklarına uygulanan orjinal versiyonunda, orta şiddetli aktiviteler için sırasıyla sıklık ve süre verilerine ( $\mathrm{SKK}=0.57$ ve $\mathrm{SKK}=0.38 ; \mathrm{p}<0.05)$ ait güvenirliğe ilişkin korelasyon katsayılarının iyi düzeyde olduğu gösterilmiştir (Telford ve diğ., 2004). Benzer şekilde Huang ve diğ. (2009) tarafindan ÇSZAA'nın Çin kültürüne uyarlamasının yapıldığı çalışmada sedanter süre, orta şiddetli fiziksel aktivite, yüksek şiddetli fiziksel aktivite ve orta-yüksek şiddetli fiziksel aktivitelere ait sınıf içi korelasyon katsayılarının 0.61 ila 0.73 arasında değiştiği görülmektedir. $(\mathrm{p}<0.05)$. Kendini değerlendirme yöntemiyle uygulanan anketlerde yüksek şiddetli fiziksel aktivitelerin doğruluğunun yüksek olduğu belirtilmiştir (Ainsworth ve diğ., 2015). Bobakova ve diğ. (2015) tarafindan yapılan çalışmada hem şiddetli fiziksel aktivite ( $\mathrm{SKK}=0.55$ ) hem de orta-yüksek şiddetli fiziksel aktivitelere ( $\mathrm{SKK}=0.52)$ ait sınıf içi korelasyon katsayısının orta düzeyde olduğu belirtilmiştir. Modifiye edilmiş Physical Activity Questionnaire for Adolescents (PAQ-A)'nın test-tekrar test güvenirliğinin çok iyi (SKK=0.78) düzeyde olduğu görülmüştür (Aggio ve diğ., 2016). Uluslararası alanyazın incelendiğinde, çocukların FA düzeylerini belirleyen ve test-tekrar test uygulamasını bir hafta arayla uygulayan çalışmaların bulguları da Çocuklar İçin Serbest Zaman Aktivite Anketi'nden elde edilen bulgulara benzer şekilde güvenirlik katsayılarının yüksek olduğunu göstermektedir.

Çocuklar açısından ele alındığında organize edilen aktivitelerin, serbest zaman aktivitelerinden daha hatırlanabilir ve tekrarlanabilir olduğu belirtilmektedir (Welk ve diğ., 2007). Telford ve diğ. (2004) ÇSZAA'nın orijinal çalışmasında futbol, tenis ve okula yürüyerek gitmek gibi genellikle organize edilen, alışagelmiş ve rutin olarak yapılan orta şiddetli 
aktivitelerinin birçoğunun güvenirlik katsayısının yüksek olduğunu (sırasıyla, $\mathrm{SKK}=0.49 ; \mathrm{SKK}=0.62 ; \mathrm{SKK}=0.85$ ) saptamışlardır. Bu bağlamda bu çalışmada ÇSZAA'da bu tür alışagelmiş ve rutin olarak yapılma eğiliminde olan aktivitelerin yer alması güvenirlik katsayılarının yüksek düzeyde elde edilmesini açıklayabilir.

Bu çalışmanın güçlü yanlarından biri çocuklar için geliştirilmiş olan birçok FA anketinin FA'nın tüm boyutlarını kapsamadığı göz önünde bulundurulduğunda, ÇSZAA'nın çocukların serbest zamanlarında yaptıkları FA'ların tüm boyutlarına ilişkin detaylı veri sunuyor olması diğeri ise 11-14 yaşları arasındaki her yaş için ayrı ayrı geçerlik ve güvenirlik katsayılarının saptanmış olmasıdır.

Geçerlik çalışmalarında birden fazla yöntem kullanılabilmektedir. Bu çalışmada sadece günlük yönteminin kullanılması bu çalışmanın sınırlılıklarından kabul edilebilir.

10 yaş ve altı çocuklar için ebeveynleri tarafından doldurulacak olan vekil anketlerin geçerlik ve güvenirlik çalışmalarının yapılması, 15 yaş ve üzerindeki çocuklar için kendini değerlendirme yöntemi ve/veya görüşme yöntemi ile geçerlik ve güvenirlik çalışmalarının yapılması, 11-14 yaşları arasındaki çocuklar için görüşme yöntemi kullanılarak ÇSZAA'nın inaktif bölümünün geçerlik çalışmasının tekrar edilmesi gelecekte yapılabilecek çalışmalara örnek olarak verilebilir. Gelecekte yapılacak olan geçerlik çalışmalarında, günlük yönteminin yanısıra objektif yöntemler de (örn. pedometre, akselerometre gibi) kullanılabilir.

\section{SONUÇ}

Sonuç olarak, ÇSZAA'nın güvenirlik bulguları incelendiğinde 11-14 yaş çocuklarında, farklı aktivite düzeylerinin tümünde (düşük, orta, yüksek ve orta-yüksek) "iyi” ve "neredeyse mükemmel” arasında değişen düzeylerde güvenirlik katsayısına sahip olduğu görülmüştür. Anketin geçerlik bulguları düşük şiddetli aktivitelerden elde edilen geçerlik katsayısının çok düşük olduğu ve güven aralığının kabul edilebilir düzeyde olmadığı ancak orta, orta-yüksek ve yüksek şiddetli aktiviteler için "iyi” ve "neredeyse mükemmel" arasında değişen geçerlik katsayılarına sahip olduğu görülmüştür. Dolayısıyla anketin düşük şiddetli aktiviteleri içeren inaktif kısmının bu yaş düzeyindeki çocuklar için kullanımının uygun olmadığı ancak orta, yüksek ve orta-yüksek şiddetli aktiviteler içeren aktif kısmının 11-14 yaş çocuklarının FA düzeylerini değerlendirmek amacıyla kullanılabileceği söylenebilir.

\section{KAYNAKLAR}

1. Aggio D, Fairclough S, Knowles Z, Graves L. (2016). Validity and reliability of a Modified English Version of the Physical Activity Auestionnaire for Adolescents. Archives of Public Health, 74(1),

2. Ainsworth BE, Haskell WL, Whitt MC, Irwin ML, Swartz AM, Strath SJ, ve diğ. (2000). Compendium of physical activities: An update of activity codes and MET intensities. Medicine and Science in Sports and Exercise, 32(9), 498-504.

3. Ainsworth BE, Cahalin L, Buman M, Ross R. (2015). The current state of physical activity assessment tools. Progress in Cardiovascular Diseases; 57(4), 387-395.

4. Altenburg TM, Chinapaw MJ. (2015). Bouts and breaks in children's sedentary time: currently used operational definitions and recommendations for future research. Preventive Medicine, 77, 1-3.

5. Anderson PM, Butcher KF. (2006). Childhood Obesity: Trends and Potential Causes. The Future of Children, 16(1), 19-45.

6. Bangsbo J, Krustrup P, Duda J, Hillman C, Andersen LB, Weiss M, ve diğ. (2016). The Copenhagen Consensus Conference 2016: children, youth, and physical activity in schools and during leisure time. British Journal of Sports Medicine, 50(19), 1177-1178.

7. Bobakova D, Hamrik Z, Badura P, Sigmundova D, Nalecz H, Kalman M. (2015). Test-retest reliability of selected physical activity and sedentary behaviour HBSC items in the Czech Republic, Slovakia and Poland. International Journal of Public Health, 60(1), 59-67.

http://www.sbd.hacettepe.edu.tr 
8. Caspersen CJ, Powell KE, Christenson GM. (1985). Physical activity, exercise, and physical fitness: definitions and distinctions for health-related research. Public Health Reports, 100(2), 126.

9. Chinapaw MJ, Mokkink LB, van Poppel MN, van Mechelen W, Terwee CB. (2010). Physical activity questionnaires for youth. Sports Medicine, 40(7), 539-63.

10. Corder K, Van Sluijs EM, Wright A, Whincup P, Wareham NJ, Ekelund U. (2009). Is it possible to assess free-living physical activity and energy expenditure in young people by self-report? The American Journal of Clinical Nutrition, 89(3), 862-870.

11. Emlek Sert Z, Bayık Temel A. (2014). İlköğretim öğrencileri için fiziksel aktivite soru formunun Türk toplumuna uyarlanması: geçerlilik ve güvenilirlik çalı̧̧ması. Dokuz Eylül Üniversitesi Hemşirelik Fakültesi Elektronik Dergisi, 7(2), 173-177.

12. Helmerhorst HHJ, Brage S, Warren J, Besson H, Ekelund U. (2012). A systematic review of reliability and objective criterion-related validity of physical activity questionnaires. International Journal of Behavioral Nutrition and Physical Activity, 9(1), 103.

13. Hills AP, Mokhtar N, Byrne NM. (2014). Assessment of physical activity and energy expenditure: an overview of objective measures. Frontiers in Nutrition, 1,5. doi: 10.3389/fnut.2014.00005.

14. Huang YJ, Wong SH, Salmon J. (2009). Reliability and validity of the modified Chinese version of the Children's Leisure Activities Study Survey (CLASS) questionnaire in assessing physical activity among Hong Kong children. Pediatric exercise science, 21(3), 339-353.

15. Janssen I. (2007). Physical activity guidelines for children and youth. Applied Physiology, Nutrition, and Metabolism, 32(S2E), 109-121.

16. Janz KF, Lutuchy EM., Wenthe P, Levy SM. (2008). Measuring activity in children and adolescents using self-report: PAQ-C and PAQA. Medicine and science in sports and exercise, 40(4), 767-772.

17. Karaca, A. (2017). Fiziksel aktivite değerlendirme yöntemleri. Ankara: Spor Yayınevi.

18. Lachat CK, Verstraeten R, Hagströmer M, Khan NC, Van NDA, Dung NQ ve diğ. (2008). Validity of two physical activity questionnaires (IPAQ and PAQA) for Vietnamese adolescents in rural and urban areas. International Journal of Behavioral Nutrition and Physical Activity, 5(1), 37.

19. Laguna M, Ruiz JR, Gallardo C, García-Pastor T, Lara MT, Aznar S. (2013). Obesity and physical activity patterns in children and adolescents. Journal of paediatrics and child health, 49(11), 942-949.

20. Landis JR, Koch GG. (1977). The measurement of observer agreement for categorical data. Biometrics, 33(1), 159-174.

21. Loprinzi PD, Cardinal BJ. (2011). Measuring children's physical activity and sedentary behaviors. Journal of Exercise Science and Fitness, $9(1), 15-23$.

22. PAGAC (Physical Activity Guidelines Advisory Committee). (2018). Physical Activity Guidelines Advisory Committee Scientific Report. Washington, DC: U.S. Department of Health and Human Services.

23. Piercy KL, Troiano RP, Ballard RM, Carlson SA, Fulton JE, Galuska DA, ve diğ. (2018). The physical activity guidelines for Americans. The Journal of the American Medical Association, 320(19), 2020-2028.

24. Porter AK, Matthews KJ, Salvo D, Kohl HW. (2017). Associations of physical activity, sedentary time, and screen time with cardiovascular fitness in United States adolescents: results from the NHANES National Youth Fitness Survey. Journal of Physical Activity and Health, 14(7), 506-512.

25. Ridley K, Olds TS, Hill A. (2006). The Multimedia activity recall for children and adolescents (MARCA): development and evaluation. International Journal of Behavioral Nutrition and Physical Activity, 3(1), 10.

26. Sirard JR, Pate RR. (2001). Physical activity assessment in children and adolescents. Sports Medicine, 31(6), 439-454.

27. Strath SJ, Bassett JrDR, Swartz AM. (2004). Comparison of the college alumnus questionnaire physical activity index with objective monitoring. Annals of Epidemiology, 14(6), 409-415.

28. Strath SJ, Kaminsky LA, Ainsworth BE, Ekelund U, Freedson PS, Gary RA, ve diğ. (2013). Guide to the assessment of physical activity: clinical and research applications: a scientific statement from the American Heart Association. Circulation, 128(20), 2259-2279.

29. Telford A, Salmon J, Jolley D, Crawford D. (2004). Reliability and validity of physical activity questionnaires for children: the Children's Leisure Activities Study Survey (CLASS). Pediatric Exercise Science, 16(1), 64-78.

30. Van der Ploeg HP, Hillsdon M. (2017). Is sedentary behaviour just physical inactivity by another name? International Journal of Behavioral Nutrition and Physical Activity, 14(1), 142.

31. Van Dyck D, Cerin E, De Bourdeaudhuij I, Hinckson E, Reis RS, Davey R., ve diğ. (2015). International study of objectively measured physical activity and sedentary time with body mass index and obesity: IPEN adult study. International Journal of Obesity, 39(2), 199.

32. Vanhees L, Lefevre J, Philippaerts R, Martens M, Huygens W, Troosters T. ve diğ. (2005). How to assess physical activity? How to assess physical fitness? European Journal of Cardiovascular Prevention and Rehabilitation, 12(2), 102-14.

33. Welk GJ, Corbin CB, Dale D. (2000). Measurement issues in the assessment of physical activity in children. Research quarterly for exercise and sport, 71(2), 59-73. 
34. Welk GJ, Wickel E, Peterson M, Heitzler CD, Fulton JE, Potter LD. (2007). Reliability and validity of questions on the youth media campaign longitudinal survey. Medicine and Science In Sports and Exercise, 39(4), 612-621.

35. WHO (World Health Organization). (2010). Global recommendations on physical activity for health. Erişim tarihi: 16.02. 2020. https://apps.who.int/iris/bitstream/handle/10665/44399/9789241599979_eng.pdf?sequence=1\&isAllowed=y

36. Wong SL, Leatherdale ST, Manske SR. (2006). Reliability and validity of a school-based physical activity questionnaire. Medicine and Science in Sports and Eexercise, 38(9), 1593-1600.

37. Yerlisu Lapa T, Certel Z, Kaplan K, Yağar G. (2016). Serbest Zaman Egzersiz Anketi’nin adolesan çağı öğrencileri için geçerlik güvenirlik çalışması. Eğitim ve Öğretim Araştırmaları Dergisi, 5, 1-9. 